\title{
Anotaciones sobre el saber/poder a propósito del cuerpo en instituciones Colombianas de educación formal*
}

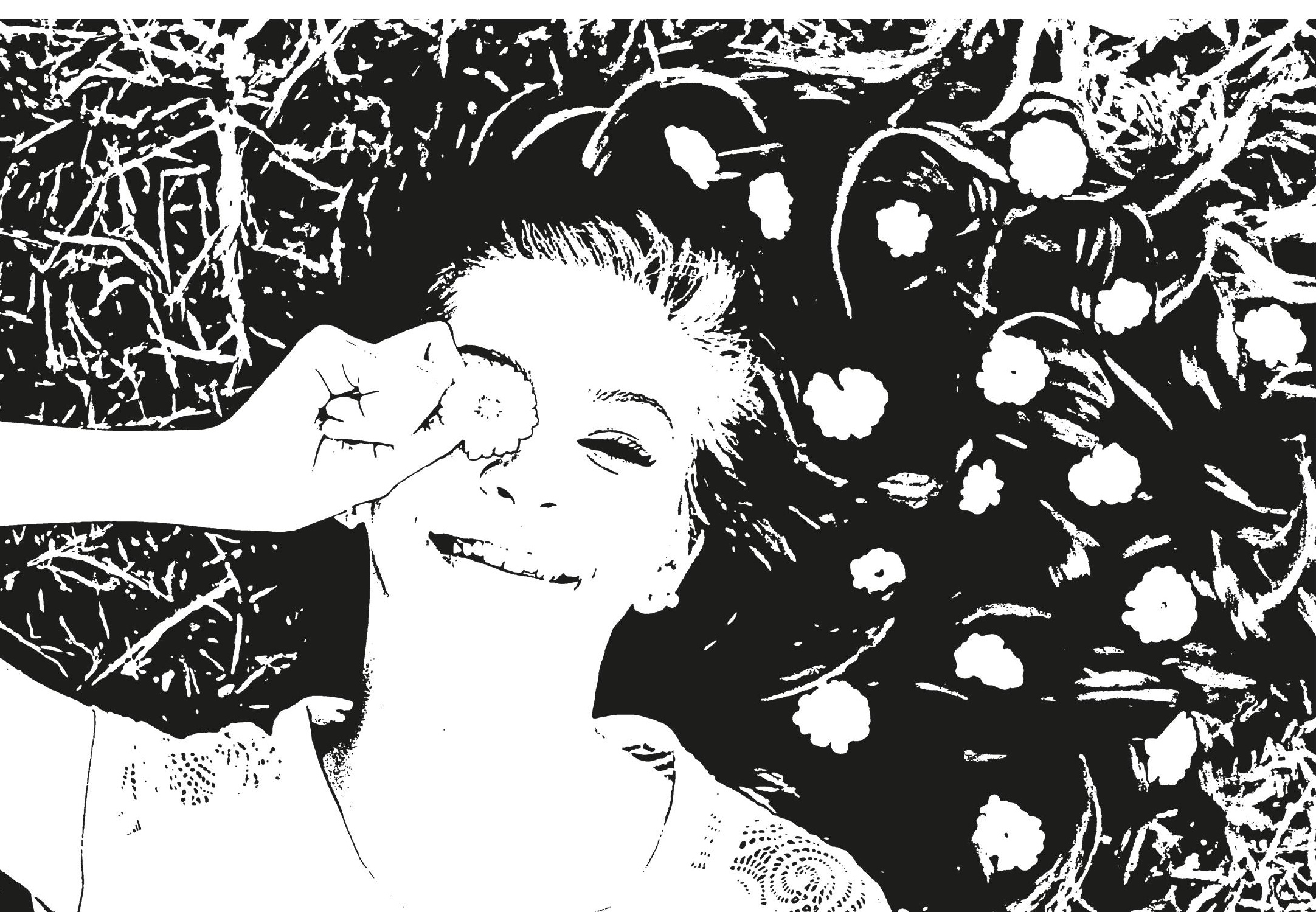




\title{
Annotations on the knowledge/power about the body in Colombian education institutions
}

\section{Anotações do conhecimento/força para o propósito do corpo nas instituições de educação Colombiana}

\begin{abstract}
Claudia Mallarino Flórez**
Universidad de San Buenaventura, Cali, Colombia.

Correo electrónico: mallarino.claudia@gmail.com

Revista Corpo-grafías: Estudios críticos de y desde los cuerpos / Volumen 4 - Número 4 / Enero - diciembre de 2017 / ISSN impreso 2390-0288, ISSN digital 2590-9398 / Bogotá, D.C., Colombia / pp. 92-109.

Fecha de recepción: 1 de octubre de 2016

Fecha de aceptación: 8 de noviembre de 2016

Doi: https://doi.org/10.14483/25909398.13665

Cómo citar este artículo: Mallarino, C. (2017, enero-diciembre). Anotaciones sobre el saber/poder a propósito del cuerpo en instituciones colombianas de educación formal. Revista Corpo-grafías: Estudios críticos de y desde los cuerpos, 4(4), pp. 92-109 / ISSN 2390-0288.

*Artículo de investigación: derivado de la tesis doctoral de la autora: "Cuerpos, sociedades e instituciones a partir de la última década del siglo XX en Colombia". Universidad Pedagógica Nacional, Universidad del Valle.

** Doctora en Educación con énfasis en Estudios del Cuerpo, doctorado Interinstitucional en Educación por la Universidad Pedagógica Nacional. Es profesora de la Maestría en Educación: Desarrollo Humano y de la Maestría en Alta Dirección de Servicios Educativos de la Universidad de San Buenaventura Cali. Ha sido profesora invitada a la Universidad de Michigan (EE.UU.) por la Maestría en Coreografía; a la Maestría en Producción Tropical Sostenible de la Universidad de los Llanos; a la Uninorte para orientar el seminario "Lenguajes expresivos en el aula, y a la Universidad del Cauca para orientar el seminario "Ecologías del cuerpo: lo instituido y lo instituyente", entre otras.
\end{abstract}

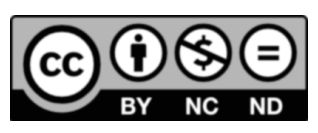




\section{Resumen}

La pregunta por las condiciones históricas de existencia de los saberes acerca del cuerpo, su lugar en la institución educativa y sus modos de producción -es decir, los momentos en que surgen, y las razones y formas en las que son producidos, instalados, organizados y utilizados- demanda la asunción de la educación como escenario pertinente de indagación para entender las maneras en que la escuela pone en juego discursividades que naturalizan modos específicos de saber acerca del cuerpo.

Palabras claves: cuerpo, escuela, saber, poder.

\section{Abstract}

The question of the existence historical conditions of the knowledge about the body, its place in the educational institution and its modes of production -that is to say, the moments in which they arise; the reasons and ways in which they are produced, installed, organized and used- demands the assumption of the education scenario as a relevant inquiry to understand the ways in which the school puts in game discursiveness that naturalize modes of knowing about the body. Keywords: body, school, knowledge, power.

\section{Resumo}

Perguntar pelas condições históricas de existência dos saberes sobre o corpo, seu lugar na instituição educativa e seu modo de produção -isto é, os momentos em que surgem; as razões e as formas como são produzidos, instalados, organizados e utilizados- demanda colocar a educação como cenário pertinente de indagação para entender a maneira como a escola põe em jogo as discursividades que situam em cada época os modos específicos de saber sobre o corpo.

Palavras chaves: corpo, escola, conhecimento, poder. 


\section{El saber/poder a propósito del cuerpo en la escuela}

La expresión saber/poder (Foucault, 1993) se refiere al evento de qué apropiarse, transmitir, hacer uso o determinar si un saber hace parte de una práctica discursiva, se da en el marco de una dinámica de resistencias y manipulaciones que lo propician u obstaculizan y de las lógicas de productividad y condiciones de posibilidad en las que se inscribe. El propósito por el cual las prácticas discursivas confieren un carácter a lo que se dice, determina modalidades discursivas. Un mismo discurso puede ser instrumento y efecto del poder, obstáculo y resistencia. El mismo discurso puesto en relación con necesidades y funciones inscritas en contextos diferentes, adquiere otros sentidos, cambia de identidad. Las prácticas discursivas en cada época y para las diferentes instancias gubernamentales, internacionales y de regulación de la educación, han configurado modos de enunciar acerca de lo corporal que han determinado tipos de cuerpo, modelos y tendencias de ser/estar/hacer/saber cuerpo y han emergido como dispositivos para su producción, control, disciplinamiento y regulación, al punto de que se podría afirmar que las culturas producen los cuerpos que necesitan y la escuela se encarga de preservarlos, o por el contrario, la cultura impone paradigmas corporales que la escuela no admite, pues ella dibuja funciones tácticas de administración del discurso, que obedecen más bien a juegos de poder/saber dentro de ella.

¿Cuáles han sido históricamente las apuestas éticas, políticas, estéticas que han hecho en la escuela los sujetos, a través de sus prácticas discursivas referidas a lo corporal?

\section{Lo dicho y lo no dicho en el marco legal - jurídico de los manuales de convivencia y los programas analíticos para su materialización en la escuela}

En el reparto de atribuciones, de jerarquización y transmisión de saberes a propósito del cuerpo, la escuela, a través de instancias como el manual de convivencia y los programas analíticos, ha configurado unas condiciones de posibilidad para estos saberes que es necesario dilucidar para entender cuáles han sido los sujetos y los discursos que históricamente la han habitado y cómo es que ha sucedido precisamente esto y no otra cosa. Estas instancias atendiendo al marco legal - jurídico que regula la educación, establecen en la escuela una práctica discursiva que determina de manera clara y concreta las intenciones y los propósitos del saber corporal que instalan allí. Al mismo tiempo, hay implícito algo que se puede inferir, que se puede suponer, que hace permeable un hálito, un aroma, una condición latente del discurso que no es ingenua ni desprevenida, por el contrario, es muy efectiva. Esta intención subyacente le da poder al saber y allí reside su efectividad. Uno de estos efectos es la naturalización ${ }^{1}$ de ciertos saberes en la práctica discursiva, una verdad corporal que es necesario aprender y por lo tanto debe ser enseñada.

\footnotetext{
1. Naturalizar es territorializar un modo de enunciación, llegar a admitir como "natural" unas maneras de referirse a algo a partir de la ilusión de que, al haber sido de esta manera por mucho tiempo, asi debe ser, asi ha sido siempre y esta permanencia per se, le otorga su validez. Naturalizar es una forma de presencia del poder, como se ve, puede no haber ninguna ley, regla o norma que diga que así se dice, pero hay una práctica que lo respalda.
} 
La Constitución Política de Colombia de 1991 consagra que la educación es un derecho de todos los colombianos y que corresponde al Estado regularla y vigilarla con el fin de velar por su calidad y por el cumplimiento de sus fines. Para lograrlo, la dirección, financiación y administración de los servicios educativos se dará en los términos que señale la ley. La Ley 115 de 1994. Ley General de Educación, es la que determina el marco legal - jurídico que responde a estos imperativos y, por consiguiente, la escuela, siguiendo la lógica normativa establecida por el Estado, determina el ámbito pedagógico - disciplinario necesario, para materializar la ley. Tanto en el marco legal - jurídico como en el ámbito pedagógico - disciplinario, lo dicho tiene un correlato en lo no dicho, lo explícito está sostenido por intenciones subyacentes donde el poder no es una "institución, y no es una estructura, no es cierta potencia de la que algunos estarían dotados: es el nombre que se presta a una situación estratégica compleja (...)" (Foucault, 1977, p. 67). Ante esta realidad es productivo inmiscuirse en las entretelas del deber ser educativo.

¿Qué verdades corporales se infieren del cuerpo legislado? ¿Qué es lo que no se dice cuando se dice a propósito del cuerpo?

\section{Los manuales de convivencia}

La Ley 115 de 1994, Ley General de Educación, decreta modos de administración y desarrollo de la vida escolar, tanto en lo concerniente a la convivencia como a la implementación de políticas y estrategias de administración del saber. Es un marco legal en cuanto dicta reglas, leyes, normas y decretos, y es jurídico dado que dictamina pautas, mecanismos y acciones concretos para hacerlos visibles y viables. Se encarga de dejar establecidos tanto los "qués" como los "cómos" y de asegurar su cumplimiento a través de un conjunto de prescripciones, sanciones y estímulos que refuerzan su carácter obligatorio e indiscutible.

En el Título IV Organización para la prestación del servicio educativo; se estipula que el manual de convivencia debe contener una definición de los derechos y deberes de los alumnos y de sus relaciones con los demás estamentos de la comunidad educativa, a partir de la consideración de aspectos como los siguientes: reglas de higiene personal y de salud pública para promover la salud individual y la prevención en el consumo de sustancias psicoactivas; criterios de respeto, valoración y compromiso para la utilización y conservación de los bienes personales y de uso colectivo; pautas de comportamiento que favorezcan la vida en común; normas de conducta para estudiantes y profesores que garanticen el respeto mutuo; instancias de diálogo y de conciliación para la resolución de conflictos; pautas de presentación personal que tienen el propósito de evitar discriminación por razones de apariencia; sanciones disciplinarias y derecho a la defensa; gobierno escolar; servicios de alimentación transporte y recreación dirigida; medios de comunicación que garanticen la libre expresión y la libertad de pensamiento; material didáctico, uniformes, seguros de vida y de salud; y, reglas para uso del bibliobanco y la biblioteca escolar (MEN, 1994). 
En este discurso de la convivencia, la salud individual y colectiva está prescrita por reglas; la valoración y el respeto de los bienes de la comunidad por criterios predeterminados; el comportamiento responde a pautas y la conducta a normas, sujetos ambos a sanción en caso de no cumplirse y con derecho a la defensa, es decir, parece asumirse desde el principio que el estudiante puede sentirse atacado y necesita defenderse. Salud, respeto, conducta y comportamiento hacen parte de lo que el estudiante debe adquirir a riesgo de ser sancionado, pertenecen al orden del tener, no del ser. Sin embargo, la resolución de conflictos dispone de instancias de diálogo y de conciliación, asuntos que demandan, más allá de obedecer y acatar normas, reglas y pautas, la presencia de cuerpos críticos, proactivos, responsables y conscientes de sus actos y consecuencias. ¿Cuáles son los espacios escolares que preparan realmente para la convivencia?

Cuando decíamos del cuerpo que sabe de sí mismo -saberes sobre el cuerpo-y por sí mismo -saberes del cuerpo-, estábamos aludiendo a un hecho que tiene profundas implicaciones, ya que al cuerpo no le basta con saber acerca de algo, es necesario que ese saber se encarne, que se llegue a la experiencia sabia. Tiene que ver con lo que en la escuela se entiende como praxis (teoría y práctica) y como aprendizaje significativo, no es nuevo y parece obvio, pero es poco probable cuando se da en contextos altamente prescriptivos. Para que el cuerpo entre en un estado experiencial, debe implicarse vivencialmente en su totalidad: sensorialidad, emocionalidad, psiquismo, espiritualidad, razón, sentido, deseo, intención y lenguaje. Lo anterior más que un cuerpo obediente reclama la presencia de un cuerpo sintiente ${ }^{2}$.

18 años después, la Secretaría de Educación ofrece orientaciones generales para la comprensión y aplicación del manual de convivencia (MEN, 2012) en el que esta es conceptualizada de la siguiente manera: "La convivencia es un efecto de las relaciones entre los integrantes de un grupo humano" (MEN, 2012, p. 1). En este planteamiento, la convivencia es un efecto, se llega a convivir como consecuencia de unos modos de saber sobre el cuerpo y desde el cuerpo, a propósito del cuerpo propio y del cuerpo del otro, en el marco de sus vicisitudes. Vemos ampliado el panorama discursivo, algo va de un siglo al otro. Se expide luego la Ley 1620 y su Decreto Reglamentario 1965 de 2013 (MEN, 2013), por el cual se crea el "Sistema Nacional de Convivencia Escolar y Formación para el Ejercicio de los Derechos Humanos, la Educación para la Sexualidad y la Prevención y Mitigación de la Violencia Escolar", que cuenta con herramientas tales como un Sistema de Información Unificado de Convivencia Escolar, donde una de sus instancias de actuación es el Comité Nacional de Convivencia Escolar.

El Comité Nacional de Convivencia Escolar armonizará y articulará las políticas, estrategias y programas y emitirá los lineamientos relacionados con la promoción y fortalecimiento de la formación para la ciudadanía, el ejercicio de los derechos humanos, sexuales y reproductivos, y la prevención y mitigación de la violencia escolar y el embarazo

2. Lo que nos preocupa no es la presencia de normas, pues ellas podrían no tener ningún efecto, el asunto que se quiere vislumbrar es la consecuencia de pensar la formación corporal con base en prescripciones aún cuando presentimos cuál es la naturaleza del saber corporal. 
en la adolescencia de los estudiantes de los niveles educativos de preescolar, básica y media. Lo anterior, a partir de las estadísticas e indicadores que arroje el Sistema de Información Unificado de Convivencia Escolar, de los resultados de la evaluación de competencias ciudadanas que realizan las pruebas SABER, y otras fuentes de información que se consideren pertinentes (MEN, 2013, hoja 5).

Según la interpretación que puede darse al decreto, los resultados recogidos del Sistema de Información Unificado de Convivencia Escolar ¿se refieren solamente a competencias ciudadanas?, no se ve cómo se va a recabar la información pertinente a derechos humanos, sexualidad, embarazo y violencia, en tanto la enunciación de la propia ley los entiende como distintos. La Ruta de Atención Integral para la Convivencia Escolar, herramienta del Sistema Nacional de Convivencia Escolar dispone también del mencionado Comité Nacional como una de sus instancias de actuación y debe adelantar, por parte de él, entre otras, las siguientes acciones:

\footnotetext{
Diseñar y divulgar las estrategias que permitan a los comités municipales, distritales y departamentales de convivencia escolar la implementación de los lineamientos consignados en este Decreto, en relación con el ajuste de los manuales de convivencia y el desarrollo de proyectos pedagógicos en competencias ciudadanas y formación para el ejercicio de los derechos humanos, sexuales y reproductivos (MEN, 2013, hoja 12).

Y, por parte del Comité Escolar de Convivencia, otra de sus instancias:

Liderar el desarrollo de iniciativas de formación de la comunidad educativa en temáticas tales como derechos humanos, sexuales y reproductivos, sexualidad, competencias ciudadanas, desarrollo infantil y adolescente, convivencia, y mediación y conciliación, para fortalecer el Sistema Nacional de Convivencia Escolar (MEN, 2013, hoja 13).
}

Revisemos con cuidado esta cadena de mando: el Comité Nacional de Convivencia Escolar dicta los lineamientos relacionados con la promoción y fortalecimiento de la formación para la ciudadanía, el ejercicio de los derechos humanos, sexuales y reproductivos, y la prevención y mitigación de la violencia escolar y el embarazo. Hasta aquí la escuela, atendiendo estos lineamientos -que son políticas generales del Estado sobre lo que debe ser la convivencia como valor nacional-, podría dejar aparecer su singularidad en su implementación, de no ser porque la Ruta de Atención Integral para la Convivencia Escolar diseña y divulga las estrategias para que los comités distritales, municipales y departamentales implementen dichos lineamientos. Les corresponde a estos comités crear las condiciones para darles vía, para pasar del "qué hacer" al "cómo hacerlo". La escuela finalmente, amparada en la implementación hecha de los lineamientos, formula proyectos pedagógicos en competencias ciudadanas y formación para el ejercicio de los derechos humanos, sexuales y reproductivos, a la luz de las iniciativas de formación que surgen del Comité Escolar de Convivencia. ¿Qué le queda a la escuela? 
Los proyectos pedagógicos en últimas pasarían a ser un conjunto de actividades que ponen en acción una política nacional, departamental, municipal y distrital, externa a la escuela y extraña a los cuerpos reales que la habitan. Se regula para prototipos somáticos. También se puede pensar que la escuela se da sus mañas para entretejer en estas tramas su idiosincrasia somática, ya que el cuerpo es una construcción simbólica, no una realidad en sí y sus representaciones, "y los saberes que se ocupan de ellas, son tributarias de un estado social, de una visión del mundo, y en el interior de ésta última, de una definición de la persona” (Le Breton, 1998, p. 13). Tal vez por eso el cuerpo es y será una verdad compleja y polimorfa que narra las historias más variadas, y su geografía (Duch \& Mélich, 2005) es la clave para la configuración de la fisonomía familiar, social, política y religiosa de la escuela y del mundo del que ella hace parte.

\section{Los programas analíticos}

Algunos de los fines referidos a la administración del saber, a los que debe atender la educación de conformidad con el artículo 67 de la Constitución Política, son:

5. La adquisición y generación de los conocimientos científicos y técnicos más avanzados, humanísticos, históricos, sociales, geográficos y estéticos, mediante la apropiación de hábitos intelectuales adecuados para el desarrollo del saber.

7. El acceso al conocimiento, la ciencia, la técnica y demás bienes y valores de la cultura, el fomento de la investigación y el estímulo a la creación artística en sus diferentes manifestaciones.

8. La creación y fomento de una conciencia de la soberanía nacional y para la práctica de la solidaridad y la integración con el mundo, en especial con Latinoamérica y el Caribe.

9. El desarrollo de la capacidad crítica, reflexiva y analítica que fortalezca el avance científico y tecnológico nacional, orientado con prioridad al mejoramiento cultural y de la calidad de la vida de la población, a la participación en la búsqueda de alternativas de solución a los problemas y al progreso social y económico del país.

10. La adquisición de una conciencia para la conservación, protección y mejoramiento del medio ambiente, de la calidad de la vida, del uso racional de los recursos naturales, de la prevención de desastres, dentro de una cultura ecológica y del riesgo y la defensa del patrimonio cultural de la Nación. 
11. La formación en la práctica del trabajo, mediante los conocimientos técnicos y habilidades, así como en la valoración del mismo como fundamento del desarrollo individual y social.

12. La formación para la promoción y preservación de la salud y la higiene, la prevención integral de problemas socialmente relevantes, la educación física, la recreación, el deporte y la utilización adecuada del tiempo libre, y

13. La promoción en la persona y en la sociedad de la capacidad para crear, investigar, adoptar la tecnología que se requiere en los procesos de desarrollo del país y le permita al educando ingresar al sector productivo (MEN, 1994, p 2).

Sabemos que una de las razones para que la naturaleza del conocimiento escolar sea fragmentaria es porque así es legislada -conocimientos científicos y técnicos más avanzados, humanísticos, históricos, sociales, geográficos y estéticos-, como también es de ley, la apropiación de hábitos intelectuales adecuados para el desarrollo del saber, lo cual no sorprende, pues la investigación en la escuela, que debería ser una actitud espontánea del cuerpo que duda, sospecha e inquiere, debe ser promovida. El Estado manda que los ciudadanos piensen y razonen adecuadamente y que lo hagan de manera repetida, hasta que esto se vuelva habitual. Los hábitos, sabemos, ya no necesitan pasar por la conciencia y la reflexión ¿cuántas veces nos hemos mordido la lengua por pensar en cómo nos estamos cepillando los dientes? Pero es que la conciencia también debe ser adquirida, se consigue en la escuela por paradójico que parezca, así mismo, la creación, la capacidad crítica, reflexiva y analítica, la salud y la higiene, son finalidades de la educación.

Es natural y humano crear, pensar, conversar, "cada vez que creamos un espacio de convivencia y reflexionamos en él a través de mirar las consecuencias de nuestro quehacer en él, puede surgir algo nuevo" (Maturana, 1996, p. 43). Todo esto que la ley determina que sean los fines de la educación viene in-corporado como parte intrínseca de la condición propiamente humana desde el momento de la concepción. Naturalmente tenemos capacidad crítica y analítica, es propio de lo humano reflexionar, tener conciencia, el cuerpo lo sabe desde que nace, la tarea de la escuela sería tal vez configurar los escenarios para que el cuerpo haga de sus saberes un saber sobre el saber, un saber sabio. Mirarse en perspectiva, analizar las consecuencias y reflexionar el quehacer, implican al sujeto de manera distinta, el saber no se adquiere como finalidad, está para ser puesto en juego y para responder por él.

Ya vimos como el manual de convivencia atiende parte de las demandas de la Constitución Política, veamos cómo se tramita lo académico concerniente al conocimiento ${ }^{3}$ que después la escuela va a materializar en los programas analíticos. La Ley 115. Ley General de Educación determina niveles y modalidades para la educación.

\footnotetext{
3. La expresión "saber" amplía el horizonte de sentido del término "conocimiento" que normalmente se asigna al saber científico y que aquí estará representado por lo que se enseña y cómo se enseña en la escuela (contenidos y metodología). Creemos que hay otros saberes que juegan un papel determinante en la posibilidad de inferir la presencia de poder, que tienen que ver más bien con las implicaciones, efectos e intenciones que tiene enseñar esto y no aquello y enseñarlo así y no de otra forma.
} 
La educación Formal, modalidad educativa en la que se inscribe este texto, se organiza en 3 niveles secuenciados:

1. La educación preescolar (mínimo 1 grado obligatorio) que corresponde al "desarrollo integral en los aspectos biológico, cognoscitivo, sicomotriz, socio-afectivo y espiritual, a través de experiencias de socialización pedagógicas y recreativas" (MEN, 1994, p. 5) tiene como objetivos específicos:

a). El conocimiento del propio cuerpo y de sus posibilidades de acción, así como la adquisición de su identidad y autonomía. b) El crecimiento armónico y equilibrado del niño, de tal manera que facilite la motricidad, el aprestamiento y la motivación para la lecto-escritura y para las soluciones de problemas que impliquen relaciones y operaciones matemáticas. c) El desarrollo de la creatividad, las habilidades y destrezas propias de la edad, como también de su capacidad de aprendizaje. d) La ubicación espacio-temporal y el ejercicio de la memoria. e) El desarrollo de la capacidad para adquirir formas de expresión, relación y comunicación y para establecer relaciones de reciprocidad y participación, de acuerdo con normas de respeto, solidaridad y convivencia. f) La participación en actividades lúdicas con otros niños y adultos. g) El estímulo a la curiosidad para observar y explorar el medio natural, familiar y social. h) El reconocimiento de su dimensión espiritual para fundamentar criterios de comportamiento. i) La vinculación de la familia y la comunidad al proceso educativo para mejorar la calidad de vida de los niños en su medio, y j) La formación de hábitos de alimentación, higiene personal, aseo y orden que generen conciencia sobre el valor y la necesidad de la salud (MEN, 1994. p. 5)

Quedan establecidos por ley los aspectos que constituyen al niño -biológico, cognoscitivo, sicomotriz, socio-afectivo y espiritual-, y cada institución deberá traducirlos en contenidos curriculares y en experiencias de socialización pedagógicas y recreativas. Vale la pena preguntarse ¿por qué lo pedagógico excluye lo recreativo? Por otro lado, la motricidad, la solución de problemas matemáticos y la motivación para la lecto-escritura, son facilitadas en la escuela inicial, por el crecimiento equilibrado y armónico, asunto que no parece menor cuando se piensa que los niños pasan más de la mitad del tiempo quietos. En esta edad, dice la ley, los niños deben adquirir formas de expresión y se les debe estimular la curiosidad, cuando uno pensaría que es propio de un niño ser curioso y usar libre y espontáneamente la lengua. También se puede pensar que estas formas de expresión se refieren a esas modalidades discursivas que se deben adquirir para entrar en las lógicas sociales y culturales: buenos días; muchas gracias; por favor; si señora; entre otras y que no pretenden abarcar toda la dimensión comunicativa de los niños. Se apela también a la espiritualidad para fundamentar criterios de comportamiento, ¿cómo se accede a la espiritualidad de un niño? es algo que queda por verse, inquietudes que nos llevan otra vez a la reflexión sobre lo corporal humano. 
2. La educación básica, dividida en primaria (cinco grados secuenciales obligatorios) y secundaria (cuatro grados secuenciales obligatorios), además de sus objetivos específicos tiene asignados nueve grupos de áreas fundamentales y obligatorias que comprenden un mínimo del $80 \%$ del plan de estudios:

1. Ciencias naturales y educación ambiental.

2. Ciencias sociales, historia, geografía, Constitución Política y democracia.

3. Educación artística.

4. Educación ética y en valores humanos.

5. Educación física, recreación y deportes.

6. Educación religiosa.

7. Humanidades, lengua castellana e idiomas extranjeros.

8. Matemáticas.

9. Tecnología e informática (MEN, 1994, p. 8).

¿Por qué se demora la persona cinco años en tener un nivel primario de conocimientos y en cambio solo cuatro años en adquirir un nivel secundario, a partir de las mismas áreas de conocimiento que son fundamentales y obligatorias para todo el país? Aparentemente todos aprenden lo mismo y de la misma manera, en el mismo tiempo y de manera gradual, el conocimiento es acumulativo y va de lo simple a lo complejo, así está previsto por el Estado. Lo mismo decía Juan Amos Comenio en el siglo XVI.

¿En qué ocupará la escuela el otro $20 \%$ ?

3. La educación media (dos grados secuenciales obligatorios) tiene como finalidad la "comprensión de las ideas y los valores universales y la preparación para el ingreso del educando a la educación superior y al trabajo" (MEN, 1994, p. 9) a través del estudio de las mismas áreas fundamentales y obligatorias de la educación básica, pero en un nivel mayor de profundidad, intensificando en algunas de ellas según su vocación e interés, lo que le da al estudiante el título de bachiller y su entrada a la educación superior. Por otro lado, el estudiante puede optar por una educación media técnica a partir de la formación calificada en especialidades como "agropecuaria, comercio, finanzas, administración, ecología, medio ambiente, industria, informática, minería, salud, recreación, turismo, deporte y las demás que requiera el sector productivo y de servicios" (MEN, 1994, p. 10) e ingresar al sector laboral. Esta formación la pueden ofrecer las instituciones de educación formal siempre y cuando dispongan de una infraestructura adecuada y obedezcan a las necesidades de su región.

Se empieza conociendo el propio cuerpo y se termina comprendiendo el universo, esta es la premisa para ingresar al mundo laboral o a la educación superior. En la educación media se aprende lo mismo que en la básica, pero con mayor profundidad, los saberes de los niños de 7 años son los mismos que los de los jóvenes de 15, solamente que, en un grado superior de dificultad, más aún, se deben intensificar los saberes de interés ccómo se tasa esta 
profundidad para dividirla en 12 grados de dificultad?, más aún, ¿cómo se organiza un mismo saber combinando variables de profundidad, dificultad e intensidad?: ¿más tiempo y más contenidos? En el bachillerato académico se puede intensificar el aprendizaje según las necesidades del estudiante, en el bachillerato técnico la formación se decide según requerimientos del sector productivo y de servicios, pues su objetivo es producir mano de obra calificada para la región. Los intereses de conocimiento que van a definir el futuro laboral del estudiante parecen estar determinados por su lugar de residencia, a menos que la escuela le pudiera ofrecer una formación básica general y luego una específica, que le permitiera acceder a otras opciones de desempeño laboral, asunto bastante improbable, pues estos ciclos de formación no son propios de la educación técnica.

Todo lo anterior va a ser relevante a la hora de mirar, por ejemplo: qué determina la escuela real que sean sus saberes admitidos y qué necesidades e intereses de aprendizaje tienen los estudiantes; qué enseñan los maestros y qué aprenden los estudiantes, es decir, qué concordancia hay entre los saberes enseñados y los saberes aprendidos, cómo controlar esta variable para que la cadena regulatoria no se desarticule; o, qué creen los padres que están aprendiendo sus hijos y qué piensa la sociedad que se debe enseñar. Los saberes que se refieren al cuerpo y los saberes del cuerpo en la escuela, le sirven a intereses distintos y están presentes y ausentes en términos de lo dicho y de lo oculto, de lo requerido y de lo prohibido y en manos de las voluntades de quienes obedecen y de quienes se resisten. Hay un poder que somete, al tiempo que hay un poder que libera.

\section{El saber/poder en la escuela real: una mirada comparada en instituciones colombianas de educación formal a partir de los manuales de convivencia y los programas analíticos}

A partir de los aspectos de ley que deben ser considerados por el manual de convivencia, cada institución escolar define las formas de su materialización en términos de su práctica discursiva. Revisados varios manuales de instituciones privadas y públicas, laicas y confesionales, mixtas y mono-genéricas ${ }^{4}$, privadas y públicas, y de diferentes estratos socioeconómicos, vemos cómo, a partir de los modos de representación de cada aspecto, se institucionaliza con detalle una identidad corporal. Como resulta demasiado extenso para el alcance de este escrito considerar todos los aspectos, detengámonos en tres de ellos: aspectos institucionales, deberes y derechos y la convivencia como contenido específico del manual:

4. Nos referimos aquí a que la institución es masculina o femenina siguiendo el criterio establecido social y estatalmente para determinar esta caracterización. No se han encontrado documentos en donde alguna institución considere algún tipo de variación al respecto. 
-Lo institucional se representa a partir de: el legado y el espíritu de los fundadores; el colegio como institución educativa; dirección de la institución y datos personales; himno nacional y oración para todos los días; filosofía, visión y misión; principios y compromisos; valores corporativos; marco legal, sentido y propósitos del manual de convivencia; referentes constitucionales, legales y jurisprudenciales; objetivos ambientales, de salud, seguridad y calidad; marco ético; el bien común y el ejercicio responsable de la libertad, entre otros. Estas expresiones se toman de los textos originales y pertenecen a diferentes instituciones.

Podemos ver cómo cada una de las instituciones se expresa atendiendo a lo que se quiere jugar como carta de presentación. Una de ellas introduce el manual hablando del colegio y de su naturaleza como institución educativa y otra recordando a su fundador; otra lo hace con el Himno Nacional y la oración para todos los días y otras, con sus principios y compromisos, visión, misión y filosofía. Mientras para una institución el componente constitucional, legal y jurisprudencial es apenas una referencia, para otra, ese mismo componente es un marco legal. Así mismo, una de las instituciones parece entender como sinónimos los conceptos "reglamento" y "manual" y a otra le parece importante ofrecer información acerca de su ubicación. Todo lo anterior nos deja ver cómo enunciar no es nombrar, hay implícito en la intención y el efecto de lo nombrado, un cuerpo insinuado. A través de esta práctica discursiva la

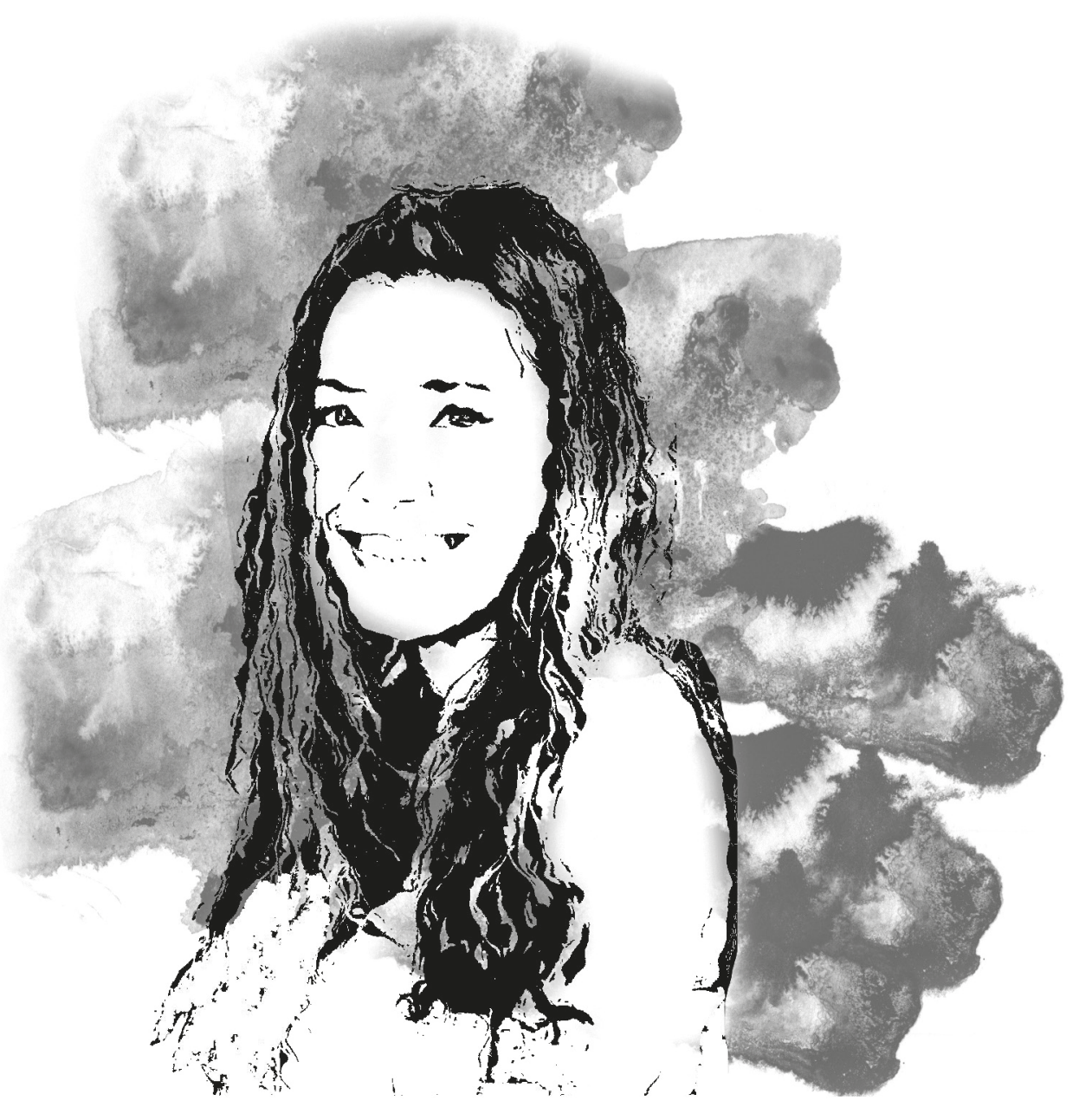


escuela tiene el poder de comunicar una idiosincrasia; una postura frente a la sociedad y al Estado; un sello personal que le dé competitividad en el mercado y reconocimiento social; un distintivo que la acredite como única, especial o recomendable; un valor de la cultura que la haga confiable; un reconocimiento del valor de la tradición que asegure en sus muros la continuidad de la identidad nacional; y el ofrecimiento de un tipo específico de formación.

-Los deberes y derechos son representados a partir de: derechos fundamentales como ideal común y derechos de los estudiantes del colegio; derechos y deberes de los directivos, derechos, deberes y estímulos de los docentes, derechos y deberes de los acudientes y padres de familia; derechos relacionados con la salud, derechos y deberes en cuanto a la prevención de sustancias psicoactivas, derechos y deberes frente a la presentación personal, derechos y deberes frente a los conflictos individuales y colectivos; de los acuerdos de convivencia; derechos, deberes y normas.

Es de anotar que ninguna institución introduce los conceptos de deber y derecho. En todas las instituciones hay un claro propósito de velar por la vida, la integridad, el buen nombre, el respeto, la salud y el libre desarrollo de la personalidad de sus estudiantes, y por esto determinan derechos y deberes específicos para ellos que ameritan ser vistos con detenimiento, lo que demanda un ejercicio dispendioso y concienzudo que no podemos hacer aquí. Nos interesa apenas dejar algunos comentarios frente a la forma cómo estos están presentados. Hay distintas estrategias para consignar estos derechos y deberes, una de ellas, presente en un buen número de manuales, es la enumeración en listados independientes e iniciando con verbos como: respetar, no someter, no ejercer, no obligar, oponerse, abstenerse, mantener un comportamiento adecuado, cumplir, ser responsable, que se le dé (...), que se le reconozca (...), recibir, elegir, participar, entre otros. Se encontraron listados que llegaban a 30 derechos y 50 deberes. Otra estrategia es la enunciación de derechos y deberes frente a una situación dada, por ejemplo: "Derechos y deberes de los alumnos frente a la utilización y conservación de los bienes personales y de uso colectivo", seguida por la enumeración de unos y otros a que haya lugar, según sea el caso. Una tercera estrategia es la caracterización de instancias de derecho del estudiante que implican varias circunstancias relacionadas y a continuación el señalamiento de deberes: "Aprender de acuerdo con sus capacidades, tanto en las clases y demás actividades académicas, como de las experiencias de la cotidianidad escolar"; para añadir a continuación: En consecuencia, son deberes de los alumnos, y seguidamente señalar deberes.

Nos interesa llamar la atención frente al efecto que puede tener listar derechos y deberes por separado, asociarlos como variables de procedimiento en una situación específica o situarlos a unos como consecuencia de los otros. En el primer caso se presenta un conjunto de prescripciones señaladas por la escuela para ser cumplidas por los estudiantes. Se reacciona a la norma más que comprenderla. Al no estar vinculados deberes y derechos en ningún tipo de causalidad, pueden entenderse como eventos separados y no llegar a asumir que los unos implican a los otros. Cuerpo con derechos o cuerpo obediente. Es importante anotar que esta institución es mixta y solamente 
-Para fomentar la convivencia una de las instituciones propone los siguientes títulos: Evaluación de la convivencia escolar, faltas leves, debido proceso, faltas graves, atenuantes y agravantes, conducto regular y estrategias formativas para faltas leves y graves; otra institución la considera dentro del capítulo de derechos y deberes en 2 instancias específicas: frente a los conflictos individuales o colectivos y frente a las faltas disciplinarias y sus procedimientos, y dice al respecto en uno de sus apartes "Todos los alumnos, cuando se equivoquen, tienen el deber de reconocer su error. Tienen el deber de presentar disculpas, de reparar el daño y el deber también, de tratar de no volver a equivocarse de la misma forma"; por último, una tercera designa una Comisión escolar de valores, bienestar y convivencia y propone desarrollar proyectos de convivencia y de capacitación en solución de conflictos y coordinar actividades especiales: excursiones, convivencias, días especiales, aprovechamiento del tiempo libre (no incluye las salidas y actividades de orden académico). A continuación, la institución determina, unilateralmente 7 aprendizajes para la convivencia que se enuncian a manera de prescripción: aprender a (...); aprender a no (...). Si a pesar de estos aprendizajes se presentan conflictos, la institución señala instancias de conciliación que deben ser aceptadas como legítimas y cumplidas.

La primera institución, como vemos, determina unilateralmente un dispositivo que evalúa primero para regular, sancionar y corregir después. En la misma vía, la segunda determina elocuentemente los deberes de los estudiantes y omite sus derechos. La tercera parece considerar dentro del proceso la voz de los estudiantes y determina actuar con base en proyectos institucionales, aunque después esta inclusión se ve bastante cuestionada. En resumen, el documento del MEN alude al manual como un pacto entre estudiantes y de ellos con las diferentes personas e instancias de la comunidad. Desde lo anterior, no habría modo de convivir y comprometerse sin la participación activa en las decisiones que caracterizan dicha convivencia, de otro modo se obedece o se reacciona.

¿A más de cuerpos obedientes estamos educando cuerpos dóciles?

Demos un breve recorrido por los programas analíticos. Veamos la caracterización de ellos en 3 instituciones:

-Institución 1: mixta, confesional, bilingüe, educación pre-escolar, básica y media vocacional, estrato socioeconómico medio y medio alto. Para el preescolar los planes de estudios para los grados se constituyen a partir de los mismos componentes. Se determinan áreas específicas de formación (religión, arte, educación física, segunda lengua, ciencias, matemáticas, etc.). Para la educación básica primaria, secundaria y media todos los planes están estructurados por los mismos elementos: enfoques para las áreas; un objeto de estudio específico del área, un propósito global o macro de formación, unos propósitos más puntuales, un estándar general que caracteriza el alcance epistemológico al que todos los estudiantes del colegio deben llegar en esa área, y unos estándares por grado, y, una estructura conceptual y evaluativa que determina contenidos y desempeños por área, por grado y por períodos -3 períodos por año-. 
-Institución 2: mixta, laica, educación preescolar, básica primaria y secundaria y media vocacional, estrato socioeconómico medio y medio bajo. El plan curricular del colegio se organiza por ciclos de formación que incluyen varios grados y así mismo se presentan los planes de estudio que constan de los siguientes elementos: presentación, objetivos, contenidos desempeños e instrumentos de evaluación (estrategias y ponderación). Las distintas materias se organizan en cinco ámbitos o campos de saber: científico-experimental; científico-social; cultural y artístico; lingüístico; y tecnológico. Para la media vocacional, que es el último ciclo, los estudiantes pueden escoger de una oferta de seminarios y cursos de variada índole en el marco de los planes de estudio del ciclo.

-Institución 3: mono-genérica, laica, preescolar, básica primaria y secundaria y media vocacional, estrato socioeconómico medio alto y alto. Los planes de estudio están estructurados con base en objetivos (cambian de año en año), temas (cambian de año en año), unidades (3 para todos los grados), dimensiones (las mismas desde preescolar hasta la media vocacional con alguna variación en su denominación en algunos grados), justificación (cambia según el grado), metodología (cambia según el grado) y proyectos transversales (los mismos para todo el colegio. Cada área se encarga de unos específicos a lo largo de toda la escolaridad)

En términos generales la escuela sigue enmarcada en los principios de la Didáctica Magna de Juan Amos Comenio del siglo XVI: todos aprendemos de la misma manera, las mismas cosas; es necesario dividir cada asunto en sus elementos y proceder paso a paso, pues la medida de las cosas es lo que el niño puede aprender y no lo que el maestro puede enseñar; que cada lección tenga un objetivo; desarrollar la idea y darle la palabra que representa; una dificultad a la vez, empezar por los sentidos y luego proveer la mente; pasar de lo conocido a lo desconocido, de lo simple a lo compuesto, de lo fácil a lo difícil, de lo complejo a lo abstracto y de lo particular a lo general. En palabras de uno de los rectores de estas instituciones la escuela sigue siendo medieval, y como reconocieron los otros 2, la escuela no ha entrado al siglo XXI.

\section{In - conclusión}

A pesar del esfuerzo de pensar el asunto educativo en una perspectiva contemporánea, el peso de la regulación es alto y la posibilidad de ignorarla muy poca. Bajo estas premisas, cabe preguntarse si puede la escuela abstraerse de las lógicas imperantes. De ahí que, situarse en términos de las demandas contemporáneas a la escuela, y de la idiosincrasia corporal de sus habitantes, parece ser imperativo si entendemos que la corporalidad humana necesita de la corporalidad de los demás; pues, en tanto cuerpos situados, es mediante ella que nos instalamos en el mundo. Es menester, entonces, para definir su pertinencia social y el tamaño de su responsabilidad, interrogar la naturaleza corporal de su propuesta educativa. 
